Analysis of microRNA precursors in multiple species by data mining techniques

Ivani de Oliveira Negrão Lopes 

SERVIÇO DE PÓS-GRADUAÇÃO DO ICMC-USP

Data de Depósito: / /

Assinatura:

\title{
Analysis of microRNA precursors in multiple species by data mining techniques
}

\author{
Ivani de Oliveira Negrão Lopes
}

Advisor: Prof. Dr. André Carlos Ponce de Leon Ferreira de Carvalho

Doctoral dissertation submitted to the Instituto de Ciências Matemáticas e de Computação - ICMC-USP, in partial fulfillment of the requirements for the degree of the Doctorate Program in Computer Science and Computational Mathematics. FINAL VERSION. 
Ficha catalográfica elaborada pela Biblioteca Prof. Achille Bassi e Seção Técnica de Informática, ICMC/USP, com os dados fornecidos pelo(a) autor(a)

de Oliveira Negrão Lopes, Ivani
/ Ivani de Oliveira Negrão Lopes; orientador
André Carlos Ponce de Leon Ferreira de Carvalho. --
São Carlos, 2014.
103 p.
Tese (Doutorado - Programa de Pós-Graduação em
Ciências de Computação e Matemática Computacional) --
Instituto de Ciências Matemáticas e de Computação,
Universidade de São Paulo, 2014.
1. Data Mining. 2. Pre-miRnA prediction. 3.
Feature sets. 4. Feature importance. 5. Ensembles.
I. Carlos Ponce de Leon Ferreira de Carvalho,
André, orient. II. Título.


Análise de precursores de microRNA em múltiplas espécies utilizando técnicas de mineração de dados

Ivani de Oliveira Negrão Lopes 



\title{
Análise de precursores de microRNA em múltiplas espécies utilizando técnicas de mineração de dados
}

\author{
Ivani de Oliveira Negrão Lopes
}

Orientador: Prof. Dr. André Carlos Ponce de Leon Ferreira de Carvalho

Tese apresentada ao Instituto de Ciências Matemáticas e de Computação - ICMC-USP, como parte dos requisitos para obtenção do título de Doutor em Ciências - Ciências de Computação e Matemática Computacional. VERSÃO REVISADA 
Ficha catalográfica elaborada pela Biblioteca Prof. Achille Bassi e Seção Técnica de Informática, ICMC/USP, com os dados fornecidos pelo(a) autor(a)

de Oliveira Negrão Lopes, Ivani
/ Ivani de Oliveira Negrão Lopes; orientador
André Carlos Ponce de Leon Ferreira de Carvalho. --
São Carlos, 2014.
103 p.
Tese (Doutorado - Programa de Pós-Graduação em
Ciências de Computação e Matemática Computacional) --
Instituto de Ciências Matemáticas e de Computação,
Universidade de São Paulo, 2014.
1. Data Mining. 2. Pre-miRnA prediction. 3.
Feature sets. 4. Feature importance. 5. Ensembles.
I. Carlos Ponce de Leon Ferreira de Carvalho,
André, orient. II. Título.




\section{Acknowledgments}

I would like to express my deep gratitude to Professor Andre Carvalho and Professor Alexander Schliep, my research supervisors, for their patient guidance, support and useful critiques of this research work. I am glad to have had two competent and kind mentors who encouraged me to explore the topic of this work under different perspectives.

My very great appreciation also goes to the following institutions: Brazilian Agricultural Research Corporation - and my research center - Embrapa Soybean, for granting me the opportunity to grow as a researcher; University of São Paulo and Rutgers The State University of New Jersey, for the infrastructure provided for the execution of this work; Conselho Nacional de Desenvolvimento Científico e Tecnológico(CNPq) for the grant awarded between May 2010 and February 2012. I extend my gratitude and appreciation to the staff of these institutions. I am particularly grateful for the encouragement and support received from my co-workers at Embrapa, specially Maria Cristina Oliveira, José Renato Farias, Alexandre Cattelan, Eliseu Binneck, Fábio Álvares, Vania Castiglioni, Divania de Lima, Claudine Dinali, Claudia Godoy, João Roberto, Neuza Avelino and Emidio Casagrande.

I am thankful to the Professors Solange Rezende, Ricardo Campello, Rodrigo Melo and Eduardo Hruschka for sharing their valuable knowledge and/or advice during my first two years at USP. I am also thankful to Professor Luis Henrique, my Master's degree supervisor, for making me believe that I have taken the right direction by getting into the computer science field.

My gratitude also goes to my dear friends and lab-mates who supported me in so many different ways. To John Wiedenhoeft, Pavel Mahmud and Rajat Shuvro, my lab-mates at Rutgers, for the many insightful discussions and for the joy we had; to Rosane Valin, Thiago Ferreira, Pablo Andretta, Danilo Horta, Elaine Farias, Rodrigo Barros, Bruno Feres, Eduardo Fraccaroli, Everlandio Fernandes and Eduardo Costa, my lab-mates at BioCom, for their friendship and support; to Fernando Zuher for the friendship and fundamental support in the last two months of stay at São Carlos; to Suzette Martinez and Eunice Au for their friendship and for their valuable orientation on my English writing.

Finally, but not less important, I would like to thank my dear cousins Maria Negrão, Raquel Negrão and Richard Noll by the support and love given to my family during our stay in New Jersey; my parents, Guilherme and Vaste Negrão, for their unconditional love, support and care and to my lovely husband Fábio Lopes, my dear son Benjamin Lopes and my dear daughter Alícia Lopes for making my journey also theirs. 

Acknowledgments ....................... . ix

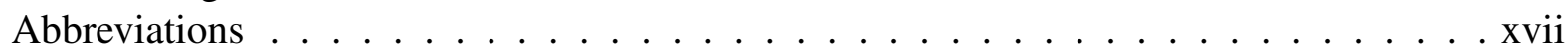

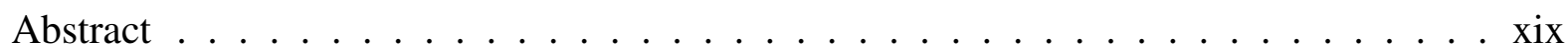

Resumo $\quad$ xxi

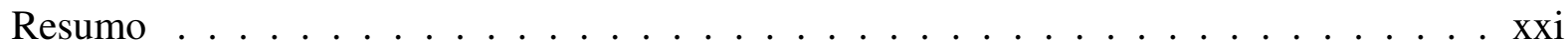

1 Introduction $\quad 1$

1.1 Historical context . . . . . . . . . . . . . . . . . . 2

1.2 What is miRNA? . . . . . . . . . . . . . . . . . 2

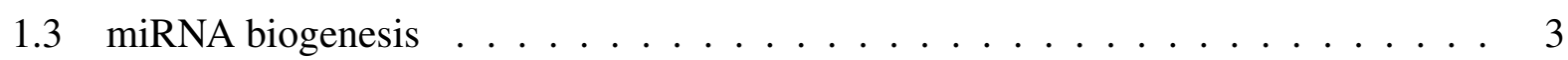

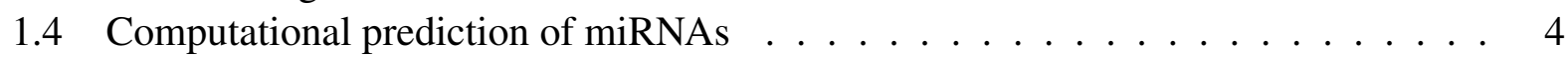

1.4.1 Ab initio genomic screening . . . . . . . . . . . . 5

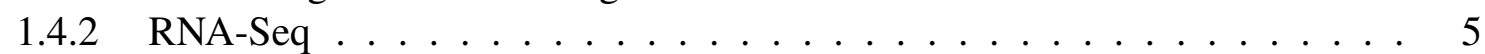

1.4 .3 miRNA abundance . . . . . . . . . . . . . . 8

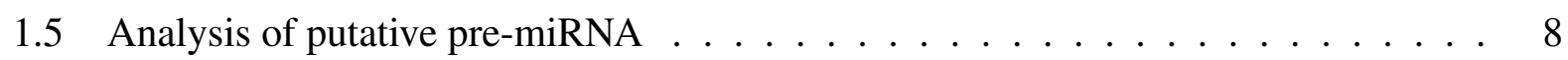

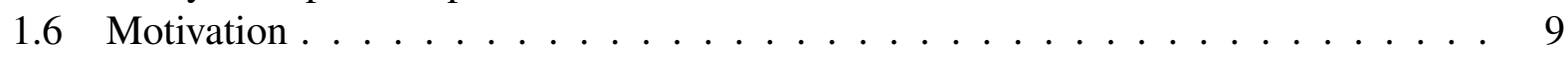

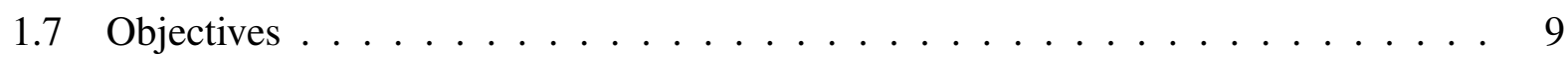

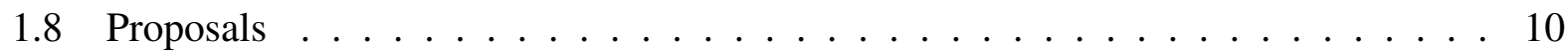

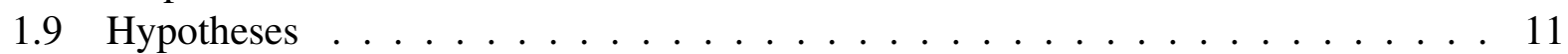

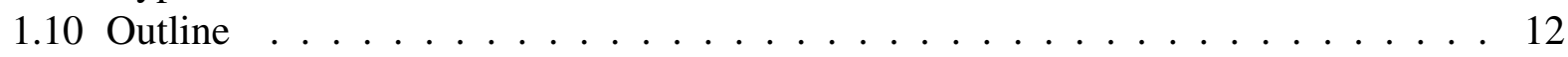

2 Background 13

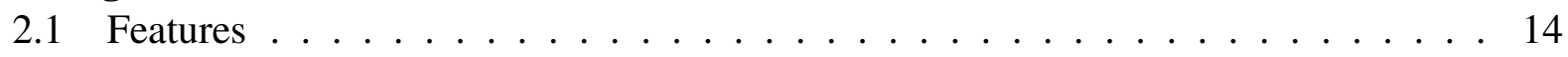

2.1.1 Sequence composition features . . . . . . . . . . . . . . . . 14

2.1.2 Structure based features . . . . . . . . . . . . . . . . . . . . 14

2.1.3 Sequence-structure based features . . . . . . . . . . . . . . . 15

2.1 .4 Thermodynamic features . . . . . . . . . . . . . . . . 15

2.1.5 Probabilistic properties . . . . . . . . . . . . . . 16

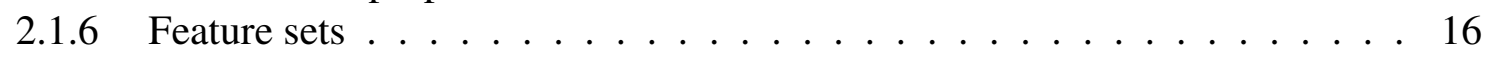

2.2 Machine learning on pre-miRNA prediction $\ldots \ldots \ldots \ldots \ldots$

2.3 Class definition . . . . . . . . . . . . . . . . . . . . 20

2.4 Material and methods . . . . . . . . . . . . . . . . . . . . . . . . . . . . . . . . . .

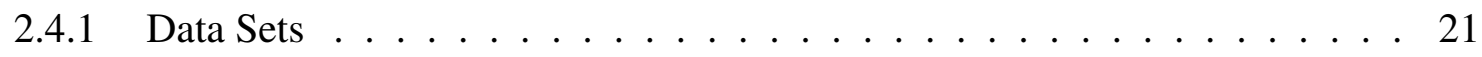

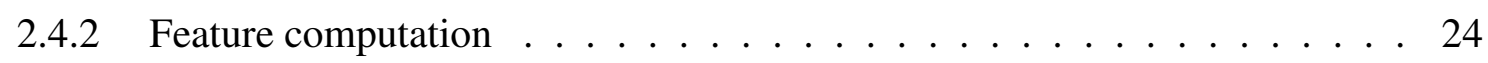

2.4 .3 Learning algorithms ....................... 24 
2.4 .4 Experiments . . . . . . . . . . . . . . . 26

2.4 .5 Feature importance and feature selection . . . . . . . . . . . 27

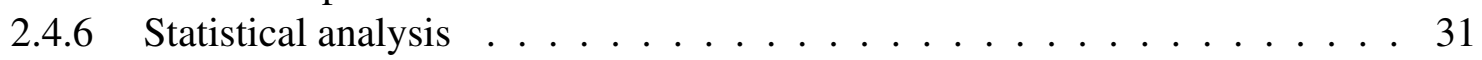

2.5 Final remarks . . . . . . . . . . . . . . . . . . . 31

3 Discriminant power $\quad 33$

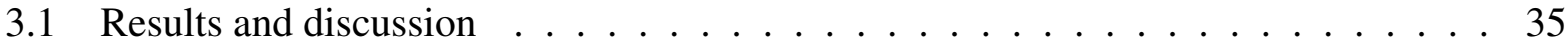

3.1.1 Effect of the training set size . . . . . . . . . . . . 35

3.1.2 Effect of feature sets and learning algorithm . . . . . . . . . . . 36

3.1.3 Feature discrimination and feature selection . . . . . . . . . . . . 37

3.1.4 Comparison with tools using the same algorithms and feature sets . . . . . 40

$3.1 .5 \mathrm{G}+\mathrm{C}$ content effect . . . . . . . . . . . . . . . 41

4 The species factor $\quad 43$

4.1 Results and discussion . . . . . . . . . . . . . . . . . . . 44

4.1.1 Generalization of feature sets accuracies . . . . . . . . . . . . . 44

4.1 .2 Important interactions . . . . . . . . . . . . . . . . . 46

4.1 .3 Species bias . . . . . . . . . . . . . . . . . . 49

4.1 .4 Cross-species models . . . . . . . . . . . . . . . . 52

4.1 .5 Classification errors $\ldots \ldots \ldots \ldots 5$

5 Ensembles $\quad 59$

5.1 Results and discussion . . . . . . . . . . . . . . . . 60

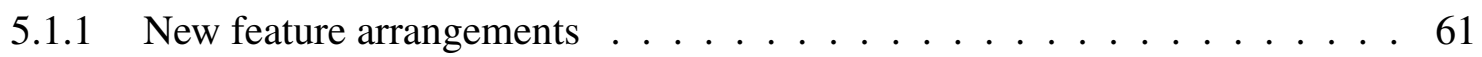

5.1 .2 Ensembles ......................... 61

5.2 Final remarks . . . . . . . . . . . . . . . . . 6 62

6 Conclusion $\quad 65$

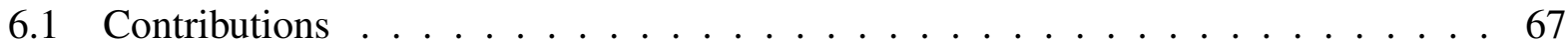

6.2 Limitations . . . . . . . . . . . . . . . . . . . 67

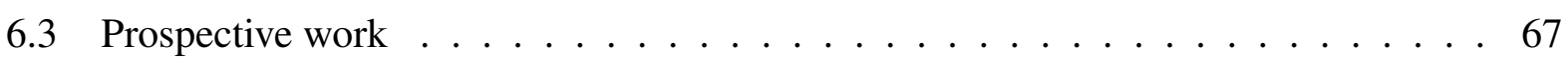

$\begin{array}{lr}\text { References } & 69\end{array}$

$\begin{array}{lll}\text { A Repositories of sequences used to excise negative examples } & 79\end{array}$

B Characterization of pre-miRNAs from 45 species $\quad 81$

$\begin{array}{lrr}\text { C } & \text { Maximum variations in accuracy } & 89\end{array}$

$\begin{array}{lll}\text { D Accuracies from cross-species predictions } & 91\end{array}$

E Clustering all classification models by species $\quad 95$

F Classification error distributions $\quad 99$ 


\section{List of Figures}

1.1 Biogenesis of canonical animal (A) and plant (B) miRNAs. . . . . . . . . . . . 4

1.2 miRNA discovery through genomic screening. The secondary structure of the window is predicted and represented in dot-bracket notation. Brackets represent paired bases and dots are unpaired bases. The bottom of the Figure shows the graphical representation of the secondary structure, predicted by RNAfold [62]. . . 6

1.3 Extrinsic similarities between the predicted secondary structure of true and pseudo miRNAs from animal (A) and plant $(\mathrm{B}) \ldots \ldots \ldots \ldots$

1.4 Identification of miRNAs using libraries of sRNA sequences. RNA reads representing miRNA:miRNA* duplex form a 2 nt $3 p$ overhang (A), but other patterns can occur, such as the observed in transitional miRNAs (B). The distribution of non miRNA reads throughout the putative hairpin is random (C). Figure adapted from $[8] \ldots \ldots \ldots \ldots \ldots$

3.1 Predictive performance produced by RF, $S V M s$ and $\mathrm{G}^{2} \mathrm{DE}$ classifiers induced with $\mathrm{FS}_{3}$ (a), and RF and SVMs classifiers induced with $\mathrm{FS}_{i}, i=1, \ldots, 7$ (b). . . . . . . 36

3.2 Average feature importance estimated during the induction of RF ensembles. Features with importance lower than five were omitted. The average feature importance drops-off quickly after the 10th feature, indicating that for each ensemble there are few features which keep a dependency relationship with the class predictor.

3.3 Predictive performance of classifiers throughout $12.5 \%$-quantile distribution of $\mathrm{G}+\mathrm{C}$ content. As the $G+C$ content increased, the sensitivity dropped, except when SVMs was trained with feature sets including $\% G+C$-based features $\left(\mathrm{FS}_{1}\right.$, $\mathrm{FS}_{2}$ and $\left.\mathrm{FS}_{7}\right) \ldots \ldots \ldots \ldots \ldots \ldots \ldots \ldots \ldots$

4.1 Frequencies of feature sets in the clusters of classification accuracies, produced by SVMs, RF and J48 algorithms. Mean $_{\mathrm{C}_{1}} \geq \ldots \geq$ Mean $_{\mathrm{C}_{5}} \ldots \ldots$. . . . . . . . . . .

4.2 Pairwise Pearson correlation coefficient of RFI vectors computed for the 85 features, for each of the 45 species. A pixel $(i, j)$ represent the Pearson correlation between the RFI vectors from species $i$ and $j$. Black pixels represent zero correlation and white pixels correspond to $100 \%$ correlation. . . . . . . . . .

4.3 Representation of $t$-test results in comparing the mean accuracies of the model species $i$ in predicting the classes of instances from $j$, where $i, j=1 . .45$. Model species are represented in the $x$-axis and test species in the $y$-axis. Cases are: $m_{i i}=m_{i j}$ (blue pixels), $m_{i i}<m_{i j}$ (green) and $m_{i i}>m_{i j}$ (red pixels). . . . . . 54 
4.4 Distribution of classification errors per species. Exclusive errors by SVMs $\left(e_{1}\right)$, RF $\left(e_{2}\right), \mathbf{J} 48\left(e_{3}\right), \mathrm{SVMs}$ and RF $\left(e_{4}\right)$, SVMs and J48 $\left(e_{5}\right), \mathrm{RF}$ and J48 $\left(e_{6}\right)$ and SVMs and RF and $\mathrm{J} 48\left(e_{7}\right) \ldots \ldots \ldots \ldots 6$

4.5 Classification errors of SVMs, RF and J48, estimated considering all species, in a total of 27000 instances. . . . . . . . . . . . . . . . . . 57

5.1 Frequency by which a model achieved accuracy in each accuracy cluster. . . . . . 63

F.1 Distribution of classification errors per species. Exclusive errors by SVMs $(e 1)$, RF (e2), J48 (e3), SVMs and RF (e4), SVMs and J48 (e5), RF and J48 (e6) and SVMs and RF and J48 $(e 7) \ldots \ldots \ldots$. . . . . . . . . . . . . . . . . . . . . . . . . .

F.2 Distribution of classification errors per species. Continuation... . . . . . . . . . . 101

F.3 Distribution of classification errors per species. Continuation... . . . . . . . . . . . 102

F.4 Classification errors of SVMs, RF and J48, estimated considering all species, in a total of 27000 instances. . . . . . . . . . . . . . . . . . . . 103 


\section{List of Tables}

2.1 Feature set composition, dimension, literature reference and associated literature tool. . . . . . . . . . . . . . . . . . . . . 1

3.1 Main characteristics of tools used as references in this work. $\mathrm{BP}=$ Number of base pairs on the stem, $M F E=$ Minimum Free Energy of the secondary structure, noML=no Multiple Loops, RR=Removed Redundancies, E-value $\leq 10^{2}=$ expected value in BLASTN against miRBase, ExpVal=Only experimentally validated precursors and $\mathrm{RF}=\mathrm{Random}$ forest. . . . . . . . . . . . . . . . . . . . 34

3.2 Predicted accuracies (Acc), sensitivities (Se), specificities (Sp), F-measures (Fm) and Mathew correlation coefficients (Mcc) of classifiers trained with 1,742 examples, presented as the mean and standard deviation (mean $\pm \mathrm{sd}$ ). Capital letters in the columns indicate the performance cluster of each feature set, within algorithm. Lower case letters in the columns indicate the cluster of each algorithms, within feature sets. Bold numbers represent the highest performances, which were not significantly different according to the clustering criteria [84] . . . . 37

3.3 Accuracies of SVMs classifiers and the computational time to compute each feature set. . . . . . . . . . . . . . . . . . . . 39

3.4 Predicted performance of tools from the literature used as references and SVMs classifiers induced with SELECT, in predicting the GEN test sets. The results are presented as the mean and the standard deviation $($ Mean $\pm S D)$. Acc=accuracy; $\mathrm{Se}=$ sensitivity; $\mathrm{Sp}=$ specificity; $\mathrm{Fm}=\mathrm{F}$-measure; $\mathrm{Mcc}=$ Mathew correlation coefficient. 40

4.1 Accuracies of different classification models. Accuracies within the same cluster are not significantly different, according to the clustering algorithm in [84], fixing $p=5 \%$. Clusters of species are given in columns $\left(\mathrm{c}_{1}-\mathrm{c}_{4}\right)$ and clusters of models in rows $\left(\mathrm{C}_{1}-\mathrm{C}_{4}\right)$. Showing SVMs.

4.2 Accuracies of different classification models. Accuracies within the same cluster are not significantly different, according to the clustering algorithm in [84], fixing $p=5 \%$. Clusters of species are given in columns $\left(\mathrm{c}_{1}-\mathrm{c}_{4}\right)$ and clusters of models in rows $\left(\mathrm{C}_{1}-\mathrm{C}_{4}\right)$. Showing $\mathrm{RF}$.

4.3 Accuracies of different classification models. Accuracies within the same cluster are not significantly different, according to the clustering algorithm in [84], fixing $p=5 \%$. Clusters of species are given in columns $\left(\mathrm{c}_{1}-\mathrm{c}_{4}\right)$ and clusters of models in rows $\left(\mathrm{C}_{1}-\mathrm{C}_{4}\right)$. Showing J48. 
4.4 Cluster centers computed as the average accuracy of each cluster and each feature set. The averages were computed from Table 4.1. . . . . . . . . . . . . . . 48

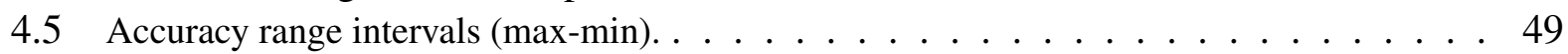

4.6 Distribution of $R F I$ intervals for different features throughout species. Omitting features with $R F I<10 \%$ for all species. . . . . . . . . . . . . . . . 51

5.1 Definition of all 44 classification models compared in this work, according to feature sets and learning algorithms. $\mathbf{M}_{i j}$ is the classifier induced with the feature set $i$ and algorithm $j, i=1 . .12$ and $j=1,2,3$, and $w_{i j}$ is the accuracies of the classifier $\mathbf{M}_{i j} . \hat{M}_{i j}$ is the predicted class by $\mathbf{M}_{i j}, \hat{M}_{i j} \in\{-1,1\}$. Emv=Ensemble majority votes, Ewv=Ensemble weighted votes. . . . . . . . . . . . . 62

A.1 Phylum, subphylum, species, acronyms for species and link to the repository containing the sequences used to extract negative examples. . . . . . . . . . . . 80

B.1 Descriptive measures of the sequence length of pre-miRNAs from species. . . . . . 82

B.2 Descriptive measures of the $Q_{\text {seq }}$ of pre-miRNAs from 45 species. . . . . . . . . 83

B.3 Descriptive measures of the $\mathrm{G}+\mathrm{C}$ content of pre-miRNAs from 45 species. . . . . . 84

B.4 Descriptive measures of the $M F E$ of pre-miRNAs from 45 species. . . . . . . . . 85

B.5 Descriptive measures of the $d G$ of pre-miRNAs from 45 species. . . . . . . . . 86

B.6 Descriptive measures of the MFEI1 of pre-miRNAs from 45 species. . . . . . . . 87

C.1 Accuracy intervals (maximum-minimum) throughout algorithms and feature sets. . 90

D.1 Average accuracies estimated from all models species induced by RF, using SELECT feature space, in predicting the labels of instances from the test sets of Cephalochordata, Urochordata, Nematoda and Hexapoda species. . . . . . . . . . 92

D.2 Average accuracies estimated from all models species induced by RF, using SELECT feature space, in predicting the labels of instances from the test sets of vertebrata species. . . . . . . . . . . . . . . . . 93

D.3 Average accuracies estimated from all models species induced by RF, using SELECT feature space, in predicting the labels of instances from the test sets of Bryozoa and Angiospermae species. . . . . . . . . . . . . . . . . . . . . . . 94

E.1 Comparison of accuracies produced by 44 classification models induced per species. Showing comparisons with SVMs models and the ensembles of 24 members. . . . . . . . . . . . . . . . . . . 96

E.2 Comparison of accuracies produced by 44 classification models induced per species. Showing comparisons of models induced with RF and the ensembles of 24 members. . . . . . . . . . . . . . . . . . . . . . . 97

E.3 Comparison of accuracies produced by 44 classification models induced per species. Showing comparisons of models induced with J48 and ensembles of 24 members. 
- bp: base-pair

- CDS: coding DNA Sequence or Coding sequence

- DNA: deoxyribonucleic acid

- FS: feature set

- MFE: minimum free energy of folding

- miRNA: microRNA

- mRNA: messenger RNA

- ncRNA: non-coding RNA

- nt: nucleotides

- OOB: out-of-bag error

- pdf: probability density functions

- pre-miRNA: microRNA precursor

- RFI: relative feature importance

- RNA: ribonucleic acid

- RNA-seq: RNA sequencing

- sRNA: small RNA

- Ss: subset of feature set

- stRNA: small temporal RNA (also microRNA)

- tmRNA: target mRNA

- UTR: Untranslated region

- 3p: 3' or 3 prime end of a genomic sequence

- 5p: 5' or 5 prime end of a genomic sequence 

RNA Sequencing has recently emerged as a breakthrough technology for microRNA (miRNA) discovery. This technology has allowed the discovery of thousands of miRNAs in a large number of species. However, despite the benefits of this technology, it also carries its own limitations, including the need for sequencing read libraries and of the genome. Differently, ab initio computational methods need only the genome as input to search for genonic locus likely to give rise to novel miRNAs. In the core of most of these methods, there are predictive models induced by using data mining techniques able to distinguish between real (positive) and pseudo (negative) miRNA precursors (pre-miRNA). Nevertheless, the applicability of current literature ab initio methods have been compromised by high false detection rates and/or by other computational difficulties. In this work, we investigated how the main aspects involved in the induction of predictive models for pre-miRNA affect the predictive performance. Particularly, we evaluate the discriminant power of feature sets proposed in the literature, whose computational costs and composition vary widely. The computational experiments were carried out using sequence data from 45 species, which covered species from eight phyla.

The predictive performance of the classification models induced using large training set sizes $(\geq 1,608)$ composed of instances extracted from real and pseudo human pre-miRNA sequences did not differ significantly among the feature sets that lead to the maximal accuracies. Moreover, the differences in the predictive performances obtained by these models, due to the learning algorithms, were neglectable. Inspired by these results, we obtained a feature set which can be computed 34 times faster than the less costly among those feature sets, producing the maximal accuracies, albeit the proposed feature set has achieved accuracy within $0.1 \%$ of the maximal accuracies. When classification models using the elements previously discussed were induced using small training sets (120) from 45 species, we showed that the feature sets that produced the highest accuracies in the classification of human sequences were also more likely to produce higher accuracies for other species. Nevertheless, we showed that the learning complexity of pre-miRNAs vary strongly among species, even among those from the same phylum. These results showed that the existence of specie specific features indicated in previous studies may be correlated with the learning complexity. As a consequence, the predictive accuracies of models induced with different species and same features and instances spaces vary largely. In our results, we show that the use of training examples from species phylogenetically more complex may increase the predictive performances for less complex species. Finally, by using ensembles of computationally less costly feature sets, we showed alternative ways to increase the predictive performance for many species while keeping the computational costs of the analysis lower than those using the feature sets from the literature. 
Since in miRNA discovery the number of putative miRNA loci is in the order of millions, the analysis of putative miRNAs using a computationally expensive feature set and or inaccurate models would be wasteful or even unfeasible for large genomes. In this work, we explore most of the learning aspects implemented in current ab initio pre-miRNA prediction tools, which may lead to the development of new efficient ab initio pre-miRNA discovery tools. 
O sequenciamento de pequenos RNAs surgiu recentemente como uma tecnologia inovadora na descoberta de microRNAs (miRNA). Essa tecnologia tem facilitado a descoberta de milhares de miRNAs em um grande número de espécies. No entanto, apesar dos benefícios dessa tecnologia, ela apresenta desafios, como a necessidade de construir uma biblioteca de pequenos RNAs, além do genoma. Diferentemente, métodos computacionais ab initio buscam diretamente no genoma regiões prováveis de conter miRNAs. A maioria desses métodos usam modelos preditivos capazes de distinguir entre os verdadeiros (positivos) e pseudo precursores de miRNA pre-miRNA - (negativos), os quais são induzidos utilizando técnicas de mineração de dados. No entanto, a aplicabilidade de métodos ab initio da literatura atual é limitada pelas altas taxas de falsos positivos e/ou por outras dificuldades computacionais, como o elevado tempo necessário para calcular um conjunto de atributos. Neste trabalho, investigamos como os principais aspectos envolvidos na indução de modelos preditivos de pre-miRNA afetam o desempenho preditivo. Particularmente, avaliamos a capacidade discriminatória de conjuntos de atributos propostos na literatura, cujos custos computacionais e a composição variam amplamente. Os experimentos computacionais foram realizados utilizando dados de sequências positivas e negativas de 45 espécies, cobrindo espécies de oito filos.

Os resultados mostraram que o desempenho preditivo de classificadores induzidos utilizando conjuntos de treinamento com 1608 ou mais vetores de atributos calculados de sequências humanas não diferiram significativamente, entre os conjuntos de atributos que produziram as maiores acurácias. Além disso, as diferenças entre os desempenhos preditivos de classificadores induzidos por diferentes algoritmos de aprendizado, utilizando um mesmo conjunto de atributos, foram pequenas ou não significantes. Esses resultados inspiraram a obtenção de um conjunto de atributos menor e que pode ser calculado até 34 vezes mais rapidamente do que o conjunto de atributos menos custoso produzindo máxima acurácia, embora a acurácia produzida pelo conjunto proposto não difere em mais de $0.1 \%$ das acurácias máximas. Quando esses experimentos foram executados utilizando vetores de atributos calculados de sequências de outras 44 espécies, os resultados mostraram que os conjuntos de atributos que produziram modelos com as maiores acurácias utilizando vetores calculados de sequências humanas também produziram as maiores acurácias quando pequenos conjuntos de treinamento (120) calculados de exemplos de outras espécies foram utilizadas. No entanto, a análise destes modelos mostrou que a complexidade de aprendizado varia amplamente entre as espécies, mesmo entre aquelas pertencentes a um mesmo filo. Esses resultados mostram que a existência de características espécificas em pre-miRNAs de certas espécies sugerida em estudos anteriores pode estar correlacionada com a complexidade de aprendizado. Consequentemente, a acurácia de modelos induzidos utilizando um mesmo conjunto de atributos e um mesmo algoritmo de aprendizado varia amplamente entre as espécies. 
Os resultados também mostraram que o uso de exemplos de espécies filogeneticamente mais complexas pode aumentar o desempenho preditivo de espécies menos complexas. Por último, experimentos computacionais utilizando técnicas de ensemble mostraram estratégias alternativas para o desenvolvimento de novos modelos para predição de pre-miRNA com maior probabilidade de obter maior desempenho preditivo do que estratégias atuais, embora o custo computacional dos atributos seja inferior.

Uma vez que a descoberta de miRNAs envolve a análise de milhares de regiões genômicas, a aplicação prática de modelos preditivos de baixa acurácia e/ou que dependem de atributos computacionalmente custosos pode ser inviável em análises de grandes genomas. Neste trabalho, apresentamos e discutimos os resultados de experimentos computacionais investigando o potencial de diversas estratégias utilizadas na indução de modelos preditivos para predição ab initio de pre-miRNAs, que podem levar ao desenvolvimento de ferramentas ab initio de maior aplicabilidade prática. 


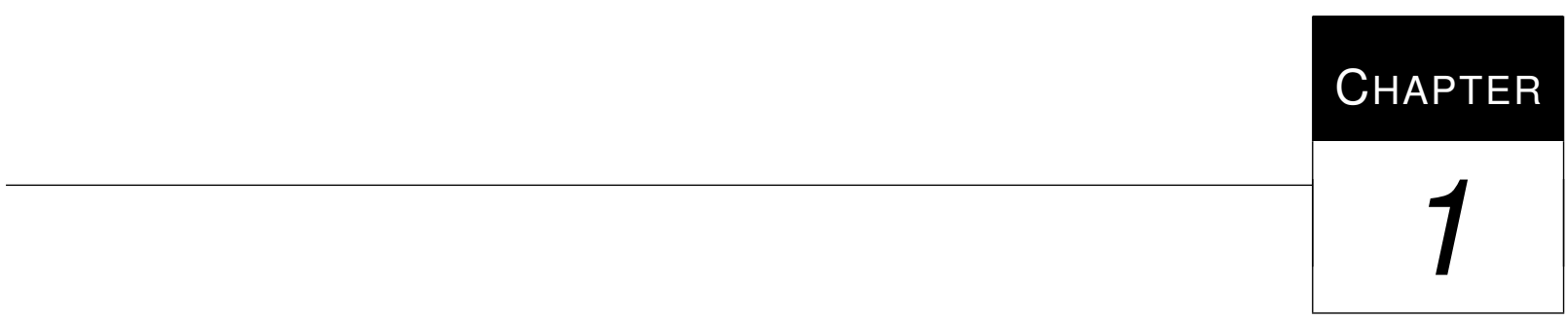

Introduction

RNA Sequencing (RNA-Seq) has recently emerged as a breakthrough technology for microRNA (miRNA) discovery. This technology has allowed the discovery of thousands of miRNAs in a large number of species. However, despite the benefits of this technology, it also carries its own limitations, including the need for the development of RNA-Seq libraries, the genome availability, posterior computational analysis and eventual experimental verification. Differently, ab initio computational methods use only the genome as input to search for genonic locus likely to give rise to novel miRNAs. As ab initio methods require only a genomic sequence as input, the main tasks in miRNA discovery using ab initio methods are the prediction of good miRNA candidates and posterior experimental validation. However, low sensitivity and/or low specificity of existing ab initio methods was reported in [24], whose methods identities were not mentioned. In another comparison, [66] showed that the specificity of microPred, a benchmark ab initio method in pre-miRNA prediction, achieved specificity of approximately $70 \%$. Predictive methods with such low specificity can make the experimental validation of the predicted instances unfeasible, considering the large number of pre-miRNAs candidates. Additionally, most ab initio methods use quantitative features computationally expensive to extract, which can make their application in large genomes unfeasible.

Since most ab initio methods have been developed using data mining techniques, the understanding of how these techniques affect the predictive performance of these methods is the first step towards the development of more effective tools. For example, the choice of a learning algorithm, or a feature spaces or a set of training instances can insert learning biases that reduce the predictive performance of unseen instances. Current literature methods have reported high 
and close predictive performances, even though they have been developed with different aims and being based on different data mining techniques.

In this work we investigated how the elements used to design classifiers to predict genomic locus likely to give rise to novel miRNAs can affect their classification performances. In the following sections, we provide a general biological background and describe the miRNA discovery problem according to the main computational approaches. The motivation, the general goals and the specific goals of this work are also described in this chapter.

\subsection{Historical context}

The central dogma of molecular biology states that biological systems are stored in hereditary units of DNA known as genes, which are copied into RNAs, which are translated into proteins $[19,61]$. The latter fulfill not only most structural and catalytic aspects but also most regulatory functions, in all cells, from microbes to mammals [70]. As a consequence, it has been believed that the primary function of genes was to serve as protein templates. However, even though the central dogma framework remains true, the growing knowledge on the role of some non-protein-coding RNA genes (ncRNAs) has unraveled many other layers of transfer information. In fact, some ncRNAs have been known for a long time and have well-established functions, whereas others are in the process of functional characterization (reviewed in [71]).

Until recently, the expression level of protein coding genes was credited to transcription factors (TFs), which are proteins that either activate or repress the transcription of other genes [15]. However, new mechanisms of pos-transcription gene regulation have been unveiled since the discovery by [3] of a small temporal RNA (stRNA), called miRNA. The excitement towards the understanding of the participation of miRNAs in the gene regulation networks is still growing [4]. In addition to the important associations found between miRNA and development and cell differentiation [53], immunity [86], tumorigenesis [11, 17] and plant development [100], evolutionary analyses have shown evidences that the amount of miRNAs is highly correlated with morphological complexity [20, 33, 45, 68, 69, 71]. Because of the important role of miRNAs in pos-transcription gene regulation, the mechanisms involving the rising of novel miRNAs and the functional characterization of known miRNAs became active research fields in molecular biology in the recent years.

\subsection{What is miRNA?}

MiRNA is a small ncRNA gene of approximately 17-25 nucleotides (nt) that modulates pos-transcription the stability of messenger RNA targets(tmRNA) and their rate of translation into proteins [44]. The mechanism of gene regulation by miRNAs was first observed through the characterization of two genetic loci involved in the control of developmental timing in 
Caenorhabditis elegans (C. elegans): lin-4 and lin-14 [4, 52]. Through genetic analysis, lin-4 has been previously known to repress the translation of lin-14.

The novelty came with the realization that lin-4 was a ncRNA processed from a short hairpin precursor and that the repression of lin-14 was induced by partial sequence complementarity between the lin-4 RNA and the lin-14 3p UTR. Subsequently, the findings that lin-4 not only regulates lin-14 but also lin-28 [75], suggested that the lin-4-lin-14 way of gene-regulatory interaction could be a more general phenomenon. Actually, the regulation of lin-14 and lin-28 by lin-4 showed that distinct genes could acquire functional lin-4 sites, indicating a potential evolutionary flexibility for this type of antisense interaction [4]. Currently, miRNAs have been found in species from almost all kingdoms.

\section{3 miRNA biogenesis}

MiRNA biogenesis is a complex process that requires the participation of several enzymes. There are many peculiarities in the biogenesis, depending on the kingdom of the species and the origin of the miRNA. The descriptions presented here are based on [100] and [5]. First, a miRNA gene is transcribed to a primary miRNA (pri-miRNA) through Polymerase II (Pol II) enzymes, which is usually a long sequence of more than several hundred nucleotides. A characteristic feature of the pri-miRNA is the fold-back, or hairpin-like shape.

In the second step, the pri-miRNA is cleaved by to a stem-loop intermediate, called pre-miRNA. The cleavage is controlled by the Drosha RNase III endonuclease in animals (Figure $1.1 \mathrm{~A}$ ) or by Dicer-like 1 enzyme (DCL1) in plants (Figure $1.1 \mathrm{~B}$ ). Third, in animals, pre-miRNAs are transported by Exportin 5 from the nucleus into the cytoplasm followed by formation of miRNA:miRNA* duplex and mature miRNAs by another RNase III-like enzyme called Dicer. Differently from animals, plant miRNAs are cleaved into miRNA:miRNA* duplex by DCL1 in the nucleus, rather than in the cytoplasm. Afterwards, the duplex is translocated into the cytoplasm by HASTY, the plant orthologus of Exportin 5.

In the cytoplasm, both plant and animal miRNAs are unwound into single strand mature miRNAs by helicase. The star strand and the loop usually degrades and the mature miRNA enters in a ribonucleoprotein complex, known as the RNA-induced silencing complex (RISC) where they regulate tmRNA. As Figure 1.1 shows, two kinds of miRNA:tmRNA pairing can occur in animals (Figure 1.1 A): near-perfect pairing, leading to the degradation of the tmRNA and partial pairing which inhibits the translation of the tmRNA. In plants (Figure $1.1 \mathrm{~B}$ ), the pairing is near-perfect, causing the tmRNA degradation.

Because the exact position of the Drosha and DCL1 signatures can rarely be identified, the indication of these sites is not a requirement for the deposit of a pre-miRNA in miRBase [29], the largest repository of experimentally validated miRNA. Concomitantly, the nomenclature 


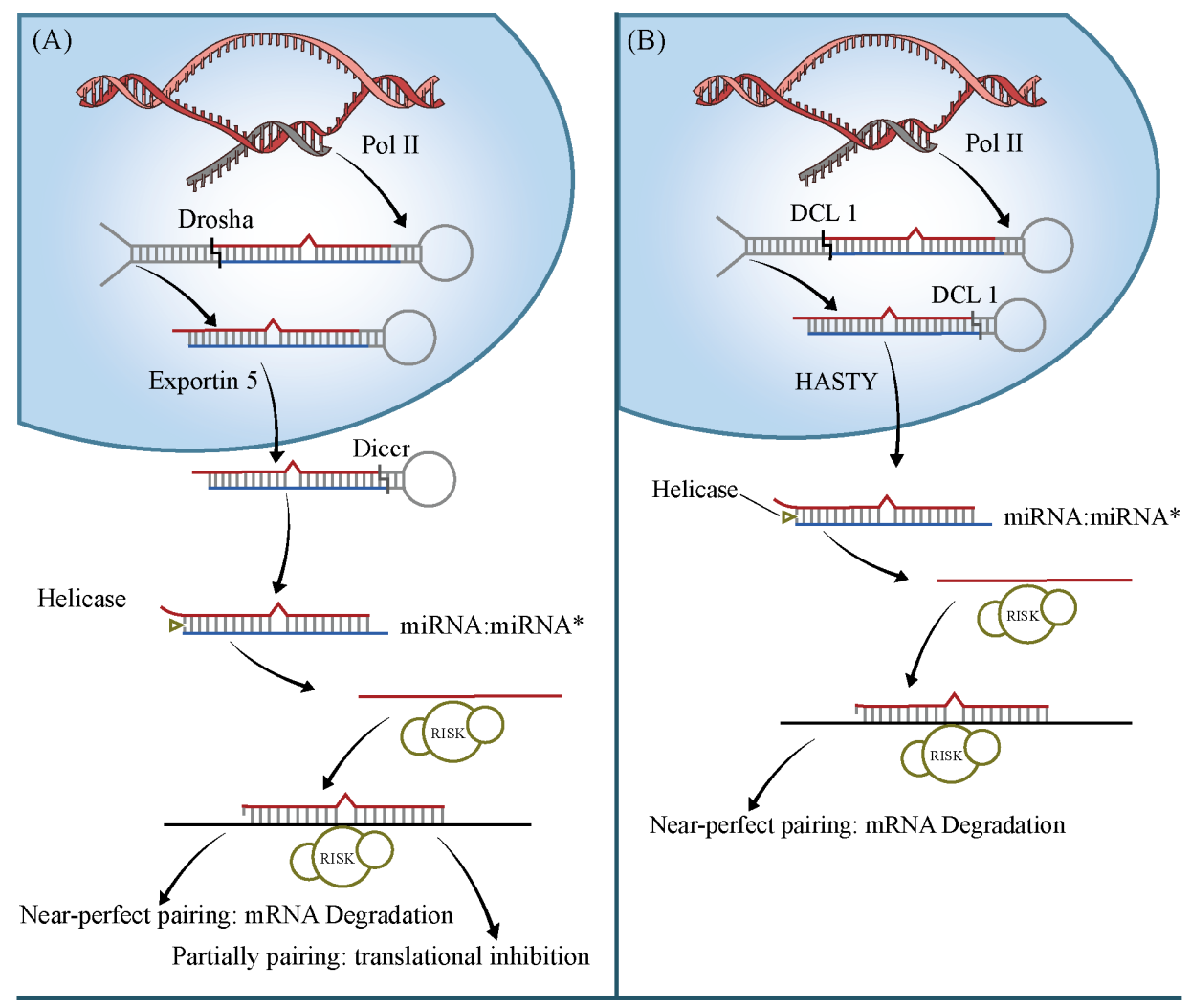

Figure 1.1: Biogenesis of canonical animal (A) and plant (B) miRNAs.

pre-miRNA used in this text may also refer to the extended hairpin, the stem-loop hairpin or the even pri-miRNA.

\subsection{Computational prediction of miRNAs}

Computational methods are important tools in miRNA discovery. They have been used in many different ways, but always aiming to reduce the amount of time and effort between the detection of putative miRNA loci and the experimental verification in vivo. As miRNAs are short genes, and consequently their short sequences are uninformative, computational detection of miRNAs from genomic sequences initially searches for sequences resembling known pre-miRNAs. The first batch of computational tools for miRNA discovery used comparative genomic approaches. Because many miRNAs are conserved in close species, these algorithms restricted the search space to conserved genomic regions obtained through multiple sequence alignment of phylogenetically close species [39, 48, 58, 77, 88]. Those approaches have the advantages of reducing the search space and the false detection rates.

Due to the discovery of species-specific [80] and non-conserved [59] miRNAs, in addition to recent studies which have indicated that miRNA evolution seems to progress at a high rate and that conserved miRNAs may represent only a small fraction [2, 56, 63], comparative genomic approaches have been put aside. The next generation of computational tools for pre-miRNA 
prediction was called ab initio, because no phylogenetic conservation was required [85]. In these approaches, putative pre-miRNAs are searched directly in the investigated genomic sequence without additional information on the conservation of specific genomic loci. To reduce the search space, some of these tools relied on the fact that many miRNAs occur in clusters in the genome to predict miRNAs neighboring other known miRNAs [66, 76, 85]. In this case, both the genome and known miRNA are used as input. Other tools such as MiRank [93] and miRNAFold [87] are "totally" ab initio, in the sense that the genome is the only input. Currently, miRNA discovery from RNA-Seq libraries became the de facto method. In the following subsections, we introduce the fundamentals and elements of miRNA prediction through ab initio genomic screening and through RNA-Seq data.

\subsubsection{Ab initio genomic screening}

MiRNA discovery using ab initio genomic screening evaluates sliding windows of length $\mathrm{L}$ throughout the genome. Since there is no parameter in the sequence level that gives any clue of what would be a plausible putative locus, the initial evaluation of the window is made at the structure level (Figure 1.2). The secondary structure represents the sequence intramolecular accommodation demanding the lowest free energy of folding (MFE), which can be predicted by an RNA folding software, such as RNAfold [62] and Mfold [101]. However, true and pseudo hairpins may have similar structural features, as illustrated in Figure 1.3 A. This figure shows the structural similarities between the predicted secondary structure of the Bombyx mori pre-miRNA bmo-mir-2855 and a pseudo hairpin taken from Bombyx mori protein coding sequences (cds) [14]. Both predicted structures have a typical hairpin with one loop, a close number of bulges and dangling ends. Likewise, Figure 1.3 B shows visual similarities between the predicted secondary structures of the Picea abies pre-miRNA pab-MIR3711 and a pseudo hairpin taken from Denio rerio cds [14]. True and pseudo hairpins have three loops, close number of bulges and dangling ends. This simple illustration shows that the distinction between true and pseudo hairpins also depends on intrinsic parameters. Moreover, pre-miRNA secondary structure varies largely from the typical hairpin-loop to highly complex structures, which is more prevalent in plants.

Since the genome content of many Eukaryotes is in the order of a billion nucleotides, the major challenge of genomic screening approaches is to discard implausible windows using inexpensive computational criteria. Additionally, the window size is usually fixed, which may not be the most efficient way to select putative hairpins, since the length distribution of pre-miRNAs varies substantially.

\subsubsection{RNA-Seq}

RNA-Seq, also called deep sequencing of transcriptome, can reveal the identities of most RNA species inside a cell, providing tens to hundreds of millions of sequence "reads" [18]. These reads 
...AUAUUUCAGAAAACAAUAAAUGUCCUCAAAGUUUGAUAAUUCUAGUCAGUUCAAUAGUAGAAGAUC AAGCACUACAAACAAACAAAACACAAAUACAGGGUAUUCUUCUAAGCCCGAUCAUUAGGCCGGCCU UGUAAGCUUCGAACUUCGCGAUUAUGUCCGGACAGACGUCGCGGACGAACUUAAAGAAG AGCGCGCCAUAGAGGCUCACCGAGGCAAGACAGGUCUUACAGAGAUUAUCAAAGCAGAAAUAGUAA CAAUCCUAAUAGUGGUAGAAGCUUUAGACAAAAUUCUGAAACUAGAUCUGUAUCACCAAGUGUUCAU GAGCACAAUAUUACUGGGCGCAAUUAUGAUCGUGACAGUAGAAGUAUGGAGACAUCUUCUGGCCGUC ACGUUC...

AGGCCGGCCUUGUAAGCUUCGAACUUCGCGAUUAUGUCCGGACAGACGUCGCGGACGAACUUAAAGAAGAGCGCGCCA

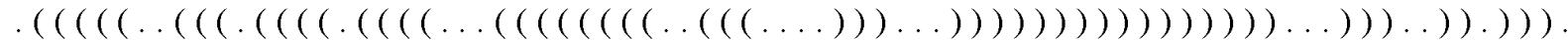

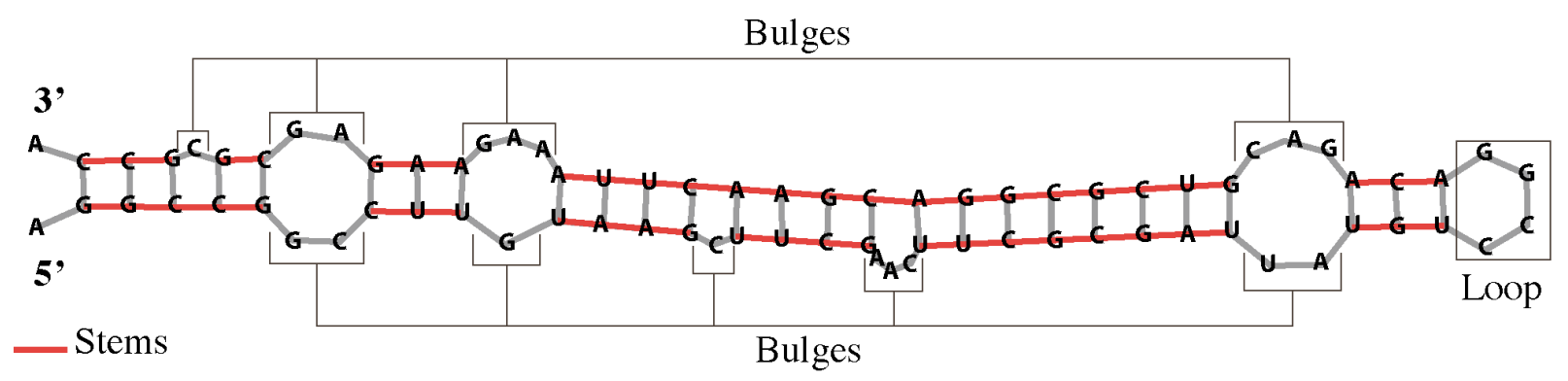

Figure 1.2: miRNA discovery through genomic screening. The secondary structure of the window is predicted and represented in dot-bracket notation. Brackets represent paired bases and dots are unpaired bases. The bottom of the Figure shows the graphical representation of the secondary structure, predicted by RNAfold [62].

(A)

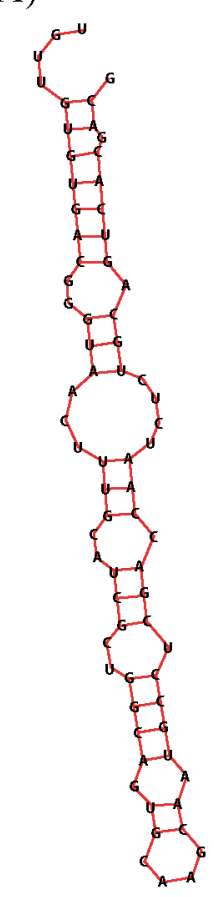

bmo-mir-2855

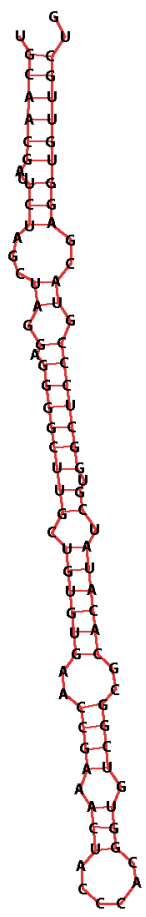

bmo-cds-pseudo
(B)

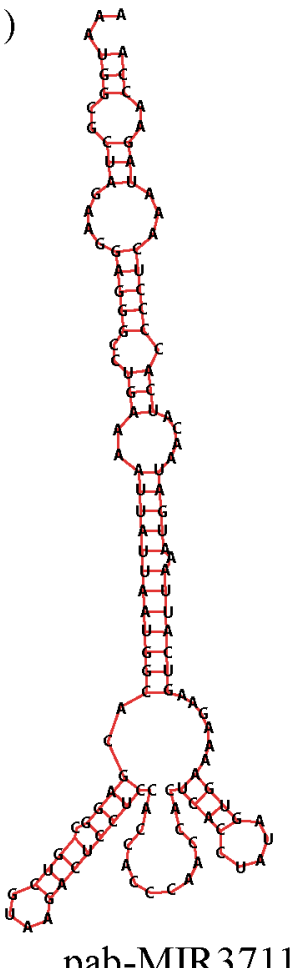

pab-MIR3711

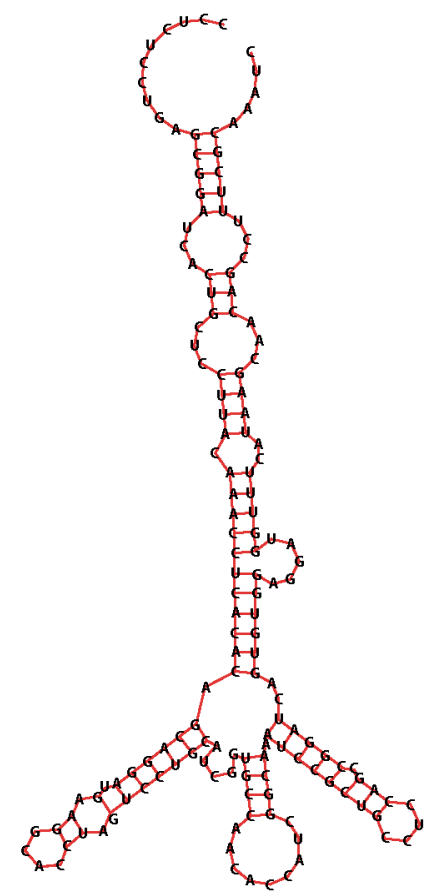

dre-cds-pseudo

Figure 1.3: Extrinsic similarities between the predicted secondary structure of true and pseudo miRNAs from animal (A) and plant (B).

provide both the sequence and the frequency of RNA molecules present in a cell. When applied to detect miRNAs, the RNA material is isolated through some procedure of size selection, such that 
only small reads (approx. $25 \mathrm{nt}$ long) are sequenced [18]. The computational challenge consists in distinguishing miRNAs from other small RNA (sRNA) types and degradation products [24].

Computational tools able to detect new miRNAs from an RNA-Seq library depend on the reference genome. Through a sequence alignment tool, such as Bowtie 2 [49], each unique read is mapped to the reference genome and the genomic locus surrounding the read is analyzed for consistency with miRNA biogenesis. This rationale assumes that the loop, the miRNA and the miRNA* strands were sequenced and their mapping pattern allows the miRNA:miRNA* $2 \mathrm{nt}$ overhang at the $3 \mathrm{p}$ ends (Figure $1.4 \mathrm{~A}$ ). Usually, the mature strand is the most frequent read followed by the star strand and the loop. However, sometimes, the star strand has similar frequency distribution to the mature strand, other times the star strand and/or the loop may not even be sequenced. The last situation can occur if the miRNA is lowly expressed in the sequenced genetic material.

(A)

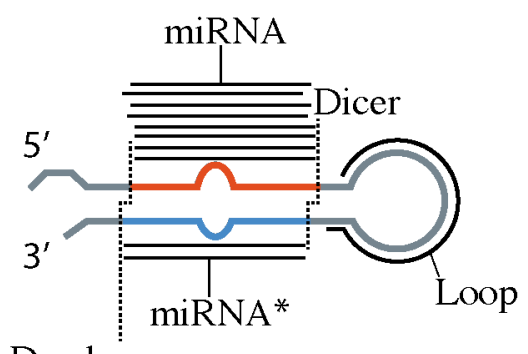

(B)

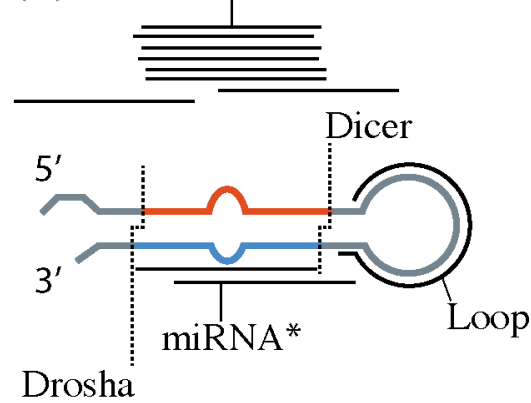

Drosha
(C)

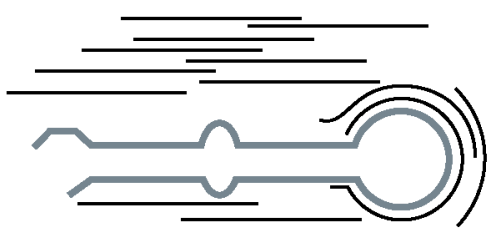

Drosha

small RNA read

Figure 1.4: Identification of miRNAs using libraries of sRNA sequences. RNA reads representing miRNA:miRNA* duplex form a 2 nt $3 p$ overhang (A), but other patterns can occur, such as the observed in transitional miRNAs (B). The distribution of non miRNA reads throughout the putative hairpin is random $(C)$. Figure adapted from [8]

When the sRNA reads are aligned in accordance with the biogenesis model and their frequency distributions are consistent with the expected pattern, the read with the highest frequency is more likely to be the mature miRNA. However, because pseudo hairpins are highly frequent in complex genomes, such as human [7], additional analyses of the putative miRNA locus based on other characteristic features, such as the energy stability, are performed to reduce false detection. Moreover, as described in [8], hairpin loci that are in the process of evolving towards a miRNA function, called transitional miRNAs, present more variation in their read distribution over the hairpin (Figure $1.4 \mathrm{~B}$ ). In these situations, subsequent analyses using characteristic features from real pre-miRNAs are fundamental to indicate if the putative miRNA 
is worth of additional experimental evidence for miRNA biogenesis [8]. Lastly, reads unlikely to be miRNAs are usually mapped to the putative hairpin randomly (Figure 1.4 C). Disadvantages of miRNA discovery from RNA-Seq libraries are the need for read library preparation and the eventual loss of information due to the low or non-expression of certain miRNAs in the genetic material used to create the reads library.

\subsection{3 miRNA abundance}

The number of miRNAs in genomes is still unclear, even in the human genome, which has currently the largest amount of known miRNAs. Estimates of the number of human miRNAs by [7] in 2005 were surpassed five years latter by the number of miRNAs deposited in miRBase release 15 [46]. Recent estimates raised evidences that approximately $60 \%$ of all human genes are regulated by miRNAs [25], distinctively to plants, whose estimate is approximately $1 \%$. Although these numbers may not be the best indicator for the amount of miRNA, they reflect the importance of this large class of regulatory genes.

\subsection{Analysis of putative pre-miRNA}

In the previous section, we mentioned that computational discovery of miRNAs depends on analyses of genomic loci called putative pre-miRNAs. These analyses use intrinsic and extrinsic features computed from true $(+)$ and pseudo/background $(-)$ pre-miRNA sequences. Each sequence is represented by a feature vector composed of features computed from the respective sequence. Hundreds of features have been used to evaluate putative pre-miRNAs. As mentioned in [2], these features are usually placed into four categories:

- sequence;

- sequence and/or structure;

- thermodynamic;

- probabilistic properties.

The definition of these features are presented in Section 2.1, Chapter 2.

Feature vectors computed from positive and negative sequences are later used to induce models to predict pre-miRNAs. Classification algorithms are the most common approach. Among them we can mention, support vector machines (SVMs) [6, 27, 34, 78, 94, 95, 97, 98], random forest (RF) [30, 42], the relaxed variable kernel density estimator (RVKDE) [13] and a generalized Gaussian components based density estimation $\left(\mathrm{G}^{2} \mathrm{DE}\right)$ [37]. Probabilistic models, like Naïve Bayes, were used to score putative miRNAs [99] and pre-miRNA [24, 55]. However, it has been suggested that this learning algorithm does not have a major effect in the predictive accuracy [2]. Moreover, once 
a classification model has been obtained, the computational cost of the analysis ends up being the computational cost of computing the feature vector representing each sequence to be evaluated. Therefore, since the induction is a one time task whereas the evaluation of putative pre-miRNA is performed on millions of sequences, the training time is irrelevant compared to the feature's computational time. As pointed out in the previous paragraph, hundreds of features have been used in different sets. However, the predictive power of these features has not been analyzed in depth [2]. Moreover, some of these features may be redundant or even irrelevant for the problem. Additionally, these features vary substantially in computational complexity.

\subsection{Motivation}

Since millions of putative pre-miRNAs can be generated from a genome such as human [7], computational evaluation needs to take into consideration the computational cost of computing the features, in addition to the predictive accuracy of the induced models. Feature sets proposed in literature papers were obtained in order to maximize classification accuracy, driven by automatic feature selection methods or by evidences of their discriminant power. However, the computational cost of features is a critical factor if they are to be computed from millions of candidates. Moreover, it is still unclear if there is a feature set in the literature more likely to produce classifiers with higher predictive performance. Another important point to consider is the absence of information on the generalization of these feature sets throughout species within and between kingdoms. Finally, the following questions need to be answered: is it possible to lower the computational cost of the computational evaluation of putative pre-miRNAs without compromising the predictive performance of the classifier?

\subsection{Objectives}

Even though research for determining the role of miRNAs in diverse biological organisms has advanced significantly, what constitutes a miRNA is still not completely elucidated, which makes computational detection of miRNA a challenging task. The major challenge is to discard implausible candidates and retain candidates likely to be a miRNA locus using low computational cost criteria. Keeping these points in mind, our general objective is:

Provide guidelines for computational analyses of putative miRNA loci with low computational cost predictive models.

To accomplish the general objective, we focused on the following specific objectives:

1. To assess the discriminant power of feature sets frequently used in six tools proposed in the literature;

2. To assess the impact of learning algorithms in the predictive accuracy of classifiers; 
3. To provide information on the generalization of the discriminant power of feature sets from the literature on animal and plant species;

4. To assess the worth of cross-species classification models;

5. To provide alternative feature sets able to reduce the time of computational analyses of putative miRNA.

\subsection{Proposals}

1. Identification of discriminant features: The predictive performance of tools found in the literature are very close, even though they use different feature sets. However, a deep comparison should be performed under the same learning algorithm, training and test sets. These investigations were conducted in the scope of human pre-miRNA, which is currently the largest set of positive examples. We compared seven feature sets from the literature, named here as $F S i$, for $i=1, \ldots, 7$.

2. Effect of learning algorithm: It has been suggested that the learning algorithms have a minor effect in the classification accuracy of pre-miRNA [2]. To investigate this statement, we compared the classification accuracy of classification models obtained in the proposal 1 , which induced using four algorithms representing different learning biases and FSi, for $i=1, \ldots, 7$.

3. Prediction of $\mathbf{G + C}$-rich sequences: $\mathrm{G}+\mathrm{C}$ content is an important feature associated with the folding of hairpin-like RNA sequences. Because $\mathrm{G}+\mathrm{C}$-rich sequences have more alternative high-energy stable binding-pairs, the prediction of the corresponding secondary structure is more complex. We investigated the sensitivity and specificity of the feature sets in the proposal 1 throughout the $12.5 \%-\mathrm{G}+\mathrm{C}$ content quantiles distribution.

4. Generalization of feature sets across species: It is a fact that the hairpin structure varies largely within and between species. To investigated the generalization of the discriminant power of the feature sets $F S i$, for $i=1, \ldots, 7$ in other species, the estimated accuracies of classifiers induced using those feature sets, three different learning algorithms and training instances of 45 species were obtained.

5. Cross-species models: Due to the low availability or lack of positive examples for many species, it is important to investigate the worth of cross-species models. To investigate a classification model induced with positive and negative examples from a species $i$ can predict with non-significantly different accuracies the class of instances from another specie $j$, with $i, j=1 \ldots 45$, the classifiers obtained under the proposal 4 was tested in the test sets of all species. 
6. Alternative feature sets: Computation of features is the most costly step in computational analysis of putative pre-miRNA. We investigated alternative feature arrangements taking into consideration their computational cost and their discriminant power.

7. Ensembles: Another way to reduce the cost of the computational analysis was tried using ensembles of computationally less expensive feature sets. Since majority and weighted votes are the most basic approaches to construct ensembles, the ensemble approaches investigated in this work were:

(a) majority vote of classifiers produced by less expensive feature sets and one specific learning algorithm;

(b) weighted vote of classifiers produced by less expensive feature sets and one specific learning algorithm. The weights were the accuracies obtained by each classifier;

(c) majority vote of classifiers produced by less expensive feature sets and three learning algorithms;

(d) weighted vote of classifiers produced by less expensive feature sets and three learning algorithms. The weights were the accuracies obtained by each classifier.

\subsection{Hypotheses}

We investigated three main hypotheses aiming to make inferences about the impact of the main factors involved in the induction of classification models for pre-miRNA prediction, namely: the feature set describing positive and negative sequences, the learning algorithm and the species whose sequences are taken to compose training sets. The first and second hypotheses were investigated by comparing the average estimated accuracies of classifiers induced using the feature sets $F S_{1}, \ldots, F S_{7}\left(\mathrm{H}_{1}\right)$ and two learning algorithms. These investigations are justified by the impossibility to infer the contribution of different feature sets and learning algorithms in the estimated accuracies of existing computational tools for pre-miRNA classification. Since those feature sets vary largely in composition and computational cost, it is important to compare their discriminant power. Moreover, as pointed in [2], learning algorithms seem to have a minor effect in the predictive accuracy of pre-miRNA classifiers. The third hypothesis is justified by the need of training examples from a species to induce classification models to predict putative pre-miRNAs from other species. These three hypotheses are symbolically given below:

1. There is no difference between the predictive performance of the classifiers induced with $F S_{1}, \ldots, F S_{7}$, under the same learning algorithm, training and test sets.

$\mathrm{H}_{0}: \mu_{F S_{i}}=\mu_{F S_{j}}$, for $i, j=1, \ldots, 7$ and $i \neq j$ and $\mu$ is the average performance.

2. Given a feature set, there is no difference between the predictive performance of the classifiers induced by algorithms $A_{1}, A_{2}, A_{3}$, under the same training and test sets. 
$\mathrm{H} 2_{0}: \mu_{A_{i}}=\mu_{A_{j}}$, for $i, j=1,2,3$ and $i \neq j$ and $\mu$ is the average performance.

3. Models induced with instances from a species $i$ can predict with non-significantly different accuracies instances from a species $j$, for $i, j=1, \ldots, 45$ and $i \neq j$.

$\mathrm{H} 3_{0}: \mu_{\text {spe }_{i}}=\mu_{\text {spe }_{j}}$, for $i, j=1, \ldots, 45$ and $i \neq j$ and $\mu$ is the average performance.

\subsection{Outline}

In Chapter 2 we present the methodological background and the experimental designs applied in the computational experiments and in the analyzes carried out in this work. The results of our investigation are presented in three chapters. In Chapter 3, the main aspects affecting the predictive performance of human pre-miRNA classifiers are identified (proposals 1-3). As a result of the experiences on the predictive power of RNA features used for pre-miRNA recognition, we obtained a lower-dimensional feature set, which achieved average sensitivity of $90 \%$ and average specificity of $95 \%$. These estimates are within $0.1 \%$ of the maximal values obtained with any feature set, while are 34 times faster to compute than the least expensive feature set which produced the highest average accuracy. The results from the proposals 4 and 5 are presented in Chapter 4. Essentially, we discuss if the prediction of pre-miRNAs from different species constitute different learning problems. Surprisingly, we show that the pre-miRNA prediction of even phylogenetically close species may correspond to different learning problems. Finally, the results from the proposals 6 and 7 are discussed in Chapter 5, where we provide evidences that ensembles of classifiers induced with computationally inexpensive feature sets can both increase the classification performance and reduce the computational costs of feature extraction. In Chapter 6, we summarize our main observations from the results discussed in chapters 3-5, where we also point out some limitations of our results, raising questions that could be an issue for further investigation and mention prospective research on the topic of miRNA discovery. 
The analysis of genomic sequences to detect loci likely to contain miRNAs using current ab initio methods has been limited by two main problems: they can produce high false detection rates and/or they require the computation of features computationally costly. We considered computationally costly feature sets those containing stability measures, which are features computed from usually 1,000 shuffled versions of each putative pre-miRNA sequences. Since the expected number of putative miRNA loci to be analyzed is usually in the order of millions, the analysis of putative microRNAs using methods leading to high false detection rates and/or using computationally expensive feature sets would be wasteful or even unfeasible for large genomes.

To seek feature sets that closely represent the true space of real and pseudo pre-miRNAs, the discriminant power of 1,385 RNA features proposed in the literature was investigated individually and in different feature sets. Particularly, the specificity of 85 out of those 1,385 features were investigated in 45 species, regarding their relevance in the classification of putative pre-miRNAs from those species. The results of these investigations, presented and discussed in chapters 3, 4 and 5, led to the proposition of alternative feature sets, named SELECT (see Chapter 3), Hyb ${ }_{37}$, $\mathrm{Hyb}_{S 7}, \mathrm{Hyb}_{17}$ and Ss1 (see Chapter 5). The main characteristic of these feature sets is the absence of stability measures. The proposed features sets are not only computationally less costly than those feature sets from the literature containing stability measures, but they produced classifiers whose predictive accuracies were equal to or greater than the predictive accuracies produced by the feature sets from the literature containing stability measures. These results suggest that the stability measures and other features might be highly correlated, although we have not computed the correlations. 
Regarding to the hypotheses $\mathrm{H} 1_{0}$ and $\mathrm{H} 2_{0}$ stated in Chapter 1 , our results corroborated with their rejection. As a consequence, we provided statistical evidences to conclude that the average accuracies of predictive models obtained with different feature sets, but the same learning algorithms, are not all equal. Likewise, we also concluded that the average accuracies of predictive models obtained with different learning algorithm, but with the same feature sets, are not all equal. Nevertheless, the differences in accuracies due to the learning algorithm are significantly lower than the differences in accuracies due to the feature sets. It is important to stress that these hypotheses where evaluated using large training data sets (1,742 instances) computed from human sequences. Therefore, the differences in accuracies due to algorithms may be larger when smaller training sets are used as it was observed in Figure 3.1 and also in Table C.1, where the accuracies were estimated using smaller training data sets (120 instances) from different species.

The hypothesis $\mathrm{H} 3_{0}$ was tested using the results of classifiers induced with training data computed from each of the 45 species, in predicting the classes of instances from other species. These results produced a $45 \times 45$ matrix, from where the $t$-test was applied to evaluate if the accuracies of a model species $i$ in predicting the classes of instances from the species $i$ and $j$, $i \neq j$, were not significantly different. As stated in Chapter 1 , the purpose of investigating this hypothesis was to identify the cases where cross-species predictive models would be viable. The rejection of $\mathrm{H}_{3}$ was associated with the model species whose accuracy was low, compared to the accuracies from other model species. As it was mentioned in Chapter 4, the results of these tests added evidences that the classes of putative pre-miRNAs from certain species are computationally easier to predict than the classes of instances from other species. Moreover, these results also showed that the choice of the training instances may be better oriented by the complexity of the available instances than by the phylogenetic proximity among the species.

Finally, this work also presented preliminary results of investigations on ensemble models for pre-miRNA prediction. The main outcome from the results of these investigations was the indication that ensembles of classifiers induced with computationally less expensive feature sets achieved accuracies in the highest accuracy cluster for a larger number of species than simple classifiers induced with feature sets containing the computationally expensive stability measures. As a consequence, ensembles were pointed as an approach to develop pre-miRNA predictive models of higher accuracies, while keeping the computation of the feature sets within the computational time of the less costly feature sets. 


\subsection{Contributions}

The main contributions from this work are:

1. The proposal of standardized methodological frameworks, described in Chapter 2, Section 2.4 allowing the isolation of controllable variation sources in the comparison of the induced models;

2. The estimates of accuracies and of computational time of existing feature sets, in Chapter 3;

3. The proposal of less costly feature sets likely to provide the same accuracies of computationally costly feature sets from the literature;

4. The experimental results were obtained for the largest number of species already investigated in the literature;

5. The investigation of cross species models, detailed in Chapter 4;

6. The detailed statistical analysis of the experimental results allowing better interpretation and inferences;

7. The analyses showing the variable learning complexity of instances from different species, which can be more relevant for classification than the phylogenetic proximity;

8. The proposal of ensemble-based approaches to increase the predictive performance and to reduce the computational time necessary to compute the feature sets.

\subsection{Limitations}

To isolate the controllable sources of variation in the computational experiments investigating the effect of the species, the training sets size was limited to 60 instances from each class, which corresponded to $2 / 3$ of the smallest positive set. Therefore, the accuracy estimates presented in this work are subject to high standard deviations, than those presented in Table 3.2. Moreover, the representativeness of positive examples may vary among species. A possible consequence would be less generalizable models, which would achieve low accuracies in the prediction of test sets, even from the same species. Nevertheless, we found no indication of such relationships, since the classes of instances from test sets from the species whose models achieved low accuracies were systematically predicted with low accuracy by other models species.

\subsection{Prospective work}

As our results showed that the learning complexity of pre-miRNAs vary throughout species and that ensembles are a promising approach to increase the predictive accuracy of classification 
models for a large number of species - a natural continuation of this work is to develop a classification tool that take advantage of these two results. Particularly, the induction of ensemble members with examples from more complex species described by different feature spaces, but still computationally less costly, may produce predictive models more likely to achieve higher accuracies in the classification of instances from any species. Along with the development of accurate pre-miRNA classification tools, new methods for the automatic excision of putative pre-miRNAs from different species are necessary to advance the discovery of miRNAs using ab initio tools. 
[1] P. S. Adhvaryu and M. Panchal. A review on diverse ensemble methods for classification. IOSR Journal of Computer Engineering, 1(4):27-32, 2012.

[2] J. Allmer and M. Yousef. Computational methods for ab initio detection of microRNAs. Frontiers in Genetics, 3:209, Jan. 2012.

[3] V. Ambros. A hierarchy of regulatory genes controls a larva-to-adult developmental switch in c. elegans. Cell, 57:49-57, 1989.

[4] V. Ambros. The evolution of our thinking about microRNAs. Nature Medicine, 14(10):1036-1040, Oct. 2008.

[5] D. P. Bartel. MicroRNAs: genomics, biogenesis, mechanism, and function. Cell, 116:281297, 2004.

[6] R. Batuwita and V. Palade. microPred: effective classification of pre-miRNAs for human miRNA gene prediction. Bioinformatics, 25(8):989-995, 2009.

[7] I. Bentwich, A. Avniel, Y. Karov, R. Aharonov, S. Gilad, O. Barad, A. Barzilai, P. Einat, U. Einav, E. Meiri, E. Sharon, Y. Spector, and Z. Bentwich. Identification of hundreds of conserved and nonconserved human microRNAs. Nature Genetics, 37(7):766-70, Jul. 2005.

[8] E. Berezikov. Evolution of microRNA diversity and regulation in animals. Nature reviews. Genetics, 12(12):846-60, Dec. 2011.

[9] E. Bonnet, J. Wuyts, P. Rouzé, and Y. Van de Peer. Evidence that microRNA precursors, unlike other non-coding RNAs, have lower folding free energies than random sequences. Bioinformatics, 20(17):2911-2917, Nov. 2004.

[10] L. Breiman. Random forests. Mach. Learn., 45(1):5-32, Oct. 2001. 
[11] S. Caramuta, L. Lee, D. M. Ozata, P. Akçakaya, P. Georgii-Hemming, H. Xie, R.-M. Amini, C. H. Lawrie, G. Enblad, C. Larsson, M. Berglund, and W.-O. Lui. Role of microRNAs and microRNA machinery in the pathogenesis of diffuse large B-cell lymphoma. Blood Cancer Journal, 3:e152, Jan. 2013.

[12] C.-C. Chang and C.-J. Lin. LIBSVM: A library for support vector machines. ACM Transactions on Intelligent Systems and Technology, 2:27:1-27:27, 2011. Software available at http://www.csie.ntu.edu.tw/ cjlin/libsvm.

[13] D. Chang, C. C. Wang, and J. W. Chen. Using a kernel density estimation based classifier to predict species-specific microRNA precursors. BMC Bioinformatics, 9(Suppl 12), 2008.

[14] J. A. Chapman, E. F. Kirkness, O. Simakov, S. E. Hampson, T. Mitros, T. Weinmaier, T. Rattei, P. G. Balasubramanian, J. Borman, D. Busam, K. Disbennett, C. Pfannkoch, N. Sumin, G. G. Sutton, L. D. Viswanathan, B. Walenz, D. M. Goodstein, U. Hellsten, T. Kawashima, S. E. Prochnik, N. H. Putnam, S. Shu, B. Blumberg, C. E. Dana, L. Gee, D. F. Kibler, L. Law, D. Lindgens, D. E. Martinez, J. Peng, P. A. Wigge, B. Bertulat, C. Guder, Y. Nakamura, S. Ozbek, H. Watanabe, K. Khalturin, G. Hemmrich, A. Franke, R. Augustin, S. Fraune, E. Hayakawa, S. Hayakawa, M. Hirose, J. S. Hwang, K. Ikeo, C. NishimiyaFujisawa, A. Ogura, T. Takahashi, P. R. H. Steinmetz, X. Zhang, R. Aufschnaiter, M.-K. Eder, A.-K. Gorny, W. Salvenmoser, A. M. Heimberg, B. M. Wheeler, K. J. Peterson, A. Böttger, P. Tischler, A. Wolf, T. Gojobori, K. A. Remington, R. L. Strausberg, J. C. Venter, U. Technau, B. Hobmayer, T. C. G. Bosch, T. W. Holstein, T. Fujisawa, H. R. Bode, C. N. David, D. S. Rokhsar, and R. E. Steele. The dynamic genome of Hydra. Nature, 464(7288):592-6, Mar. 2010.

[15] K. Chen and N. Rajewsky. The evolution of gene regulation by transcription factors and microRNAs. Nature reviews. Genetics, 8(2):93-103, Feb. 2007.

[16] Y.-W. Chen and C.-J. Lin. Combining SVMs with Various Feature Selection Strategies. In I. Guyon, M. Nikravesh, S. Gunn, and L. A. Zadeh, editors, Feature Extraction, volume 207 of Studies in Fuzziness and Soft Computing, chapter 13, pages 315-324. Springer Berlin Heidelberg, Berlin, Heidelberg, 2006.

[17] W. C. S. Cho. MicroRNAs in cancer - from research to therapy. Biochimica et Biophysica Acta, 1805(2):209-17, Apr. 2010.

[18] Y. Chu and D. R. Corey. RNA sequencing: platform selection, experimental design, and data interpretation. Nucleic Acid Therapeutics, 22(4):271-4, Aug. 2012.

[19] F. Crick. Central Dogma of Molecular Biology, 1970.

[20] K. De Mulder and E. Berezikov. Tracing the evolution of tissue identity with microRNAs. Genome biology, 11(3):111, Jan. 2010. 
[21] T. G. Dietterich. Ensemble Methods in Machine Learning. Lecture Notes in Computer Science, 1857:1-15, 2000.

[22] J. Ding, S. Zhou, and J. Guan. MiRenSVM: towards better prediction of microRNA precursors using an ensemble SVM classifier with multi-loop features. BMC Bioinformatics, 11 Suppl 1:S11, Jan. 2010.

[23] E. Freyhult, P. P. Gardner, and V. Moulton. A comparison of rna folding measures. BMC Bioinformatics, 6, 2005.

[24] M. R. Friedländer, W. Chen, C. Adamidi, J. Maaskola, R. Einspanier, S. Knespel, and N. Rajewsky. Discovering microRNAs from deep sequencing data using miRDeep. Nature Biotechnology, 26(4):407-15, Apr. 2008.

[25] R. C. Friedman, K. K.-H. Farh, C. B. Burge, and D. P. Bartel. Most mammalian mRNAs are conserved targets of microRNAs. Genome Research, 19(1):92-105, Jan. 2009.

[26] H. H. Gan, D. Fera, J. Zorn, N. Shiffeldrim, M. Tang, U. Laserson, N. Kim, and T. Schlick. RAG: RNA-as-graphs database-concepts, analysis, and features. Bioinformatics., 20:12851291, 2004.

[27] D. Gerlach, E. V. Kriventseva, N. Rahman, C. E. Vejnar, and E. M. Zdobnov. miROrtho: computational survey of microRNA genes. Nucleic Acids Research, 37(Database issue):gkn707+, Jan. 2009.

[28] M. Ghodsi, B. Liu, and M. Pop. DNACLUST: accurate and efficient clustering of phylogenetic marker genes. BMC Bioinformatics, 12(1):271+, 2011.

[29] S. Griffiths-Jones. The microRNA Registry. Nucleic Acids Research, 32(Database issue), Jan. 2004.

[30] A. Gudyś, M. W. Szcześniak, M. Sikora, and I. Makalowska. HuntMi: an efficient and taxon-specific approach in pre-miRNA identification. BMC Bioinformatics, 14(1):83, 2013.

[31] I. Guyon, J. Weston, S. Barnhill, and V. Vapnik. Gene selection for cancer classification using support vector machines. Machine Learning, 46(1-3):389-422, Jan. 2002.

[32] M. Hackenberg, N. Rodríguez-Ezpeleta, and A. M. Aransay. miRanalyzer: an update on the detection and analysis of microRNAs in high-throughput sequencing experiments. Nucleic Acids Research, 39(Web Server issue):W132-8, Jul. 2011.

[33] A. M. Heimberg, L. F. Sempere, V. N. Moy, P. C. Donoghue, and K. J. Peterson. MicroRNAs and the advent of vertebrate morphological complexity. Proc Natl Acad Sci USA, 105:2946$2950,2008$. 
[34] J. Hertel and P. F. Stadler. Hairpins in a Haystack: recognizing microRNA precursors in comparative genomics data. Bioinformatics, 22(14):197-202, Jul. 2006.

[35] I. L. Hofacker. Vienna RNA secondary structure server. Nucleic Acids Research, 31(13):3429-3431, Jul. 2003.

[36] K. Hornik, C. Buchta, and A. Zeileis. Open-source machine learning: R meets Weka. Computational Statistics, 24(2):225-232, 2009.

[37] C.-H. Hsieh, D. T.-H. Chang, C.-H. Hsueh, C.-Y. Wu, and Y.-J. Oyang. Predicting microRNA precursors with a generalized Gaussian components based density estimation algorithm. BMC Bioinformatics, 11 Suppl 1:S52, Jan. 2010.

[38] C.-H. Hsieh, D. T.-H. Chang, and Y.-J. Oyang. Data classification with a generalized gaussian components based density estimation algorithm. In Proceedings of the 2009 International Joint Conference on Neural Networks, IJCNN'09, pages 2910-2917, Piscataway, NJ, USA, 2009. IEEE Press.

[39] T. H. Huang, B. Fan, M. Rothschild, Z. L. Hu, K. Li, and S. H. Zhao. MiRFinder: an improved approach and software implementation for genome-wide fast microRNA precursor scans. BMC Bioinformatics, 8(1):341+, Sep. 2007.

[40] S. I. Inc. SAS/STAT ®9.2 User's Guide. SAS Institute Inc., Cary, NC, USA, 2008.

[41] E. G. Jelihovschi, J. C. Faria, and I. B. Allaman. The ScottKnott Clustering Algorithm. Universidade Estadual de Santa Cruz - UESC, Ilheus, Bahia, Brasil, 2013.

[42] P. Jiang, H. Wu, W. Wang, W. Ma, X. Sun, and Z. Lu. MiPred: classification of real and pseudo microRNA precursors using random forest prediction model with combined features. Nuc. Ac. Res., 35(suppl 2):W339-W344, Jul. 2007.

[43] T. K. K. Kamanu, A. Radovanovic, J. A. C. Archer, and V. B. Bajic. Exploration of miRNA families for hypotheses generation. Scientific Reports, 3:2940, Jan. 2013.

[44] M. Khorshid, J. Hausser, M. Zavolan, and E. van Nimwegen. A biophysical miRNA-mRNA interaction model infers canonical and noncanonical targets. Nature Methods, 10(3):253-5, Mar. 2013.

[45] M. V. Koerner, F. M. Pauler, R. Huang, and D. P. Barlow. The function of non-coding RNAs in genomic imprinting. Development (Cambridge, England), 136(11):1771-1783, Jun. 2009.

[46] A. Kozomara and S. Griffiths-Jones. miRBase: integrating microRNA annotation and deepsequencing data. Nucleic Acids Research, 39(suppl 1):D152-D157, Jan. 2011. 
[47] A. Kozomara and S. Griffiths-Jones. miRBase: annotating high confidence microRNAs using deep sequencing data. Nucleic Acids Research, 42(Database issue):D68-73, Jan. 2014.

[48] E. Lai, P. Tomancak, R. Williams, and G. Rubin. Computational identification of Drosophila microRNA genes. Genome Biology, 4(7.R42):1-20, 2003.

[49] B. Langmead and S. L. Salzberg. Fast gapped-read alignment with Bowtie 2. Nat Meth, 9(4):357-359, Apr. 2012.

[50] S. Y. Le, J. H. Chen, and J. Maizel. Thermodynamic stability and statistical significance of potential stem-loop structures situated at frameshift sites of retroviruses. Nucleic Acids Research, 17:6143-6152, 1989.

[51] M. Leclercq, A. B. Diallo, and M. Blanchette. Computational prediction of the localization of microRNAs within their pre-miRNA. Nucleic Acids Research, 41(15):7200-11, Aug. 2013.

[52] R. C. Lee, R. L. Feinbaum, and V. Ambros. The C. elegans heterochronic gene lin-4 encodes small RNAs with antisense complementarity to lin-14. Cell, 75(5):843-54, Dec. 1993.

[53] B. S. Letzen, C. Liu, N. V. Thakor, J. D. Gearhart, A. H. All, and C. L. Kerr. MicroRNA expression profiling of oligodendrocyte differentiation from human embryonic stem cells. PLoS ONE, 5(5):e10480, May. 2010.

[54] W.-S. Leung, M. C. M. Lin, D. W. Cheung, and S. M. Yiu. Filtering of false positive microRNA candidates by a clustering-based approach. BMC Bioinformatics, 9 Suppl 12:S3, Jan. 2008.

[55] N. Li, X. You, T. Chen, S. D. Mackowiak, M. R. Friedländer, M. Weigt, H. Du, A. GogolDöring, Z. Chang, C. Dieterich, Y. Hu, and W. Chen. Global profiling of miRNAs and the hairpin precursors: insights into miRNA processing and novel miRNA discovery. Nucleic Acids Research, 41(6):3619-3634, Feb. 2013.

[56] H. Liang and W.-H. Li. Lowly expressed human microRNA genes evolve rapidly. Molecular Biology and Evolution, 26(6):1195-8, Jun. 2009.

[57] A. Liaw and M. Wiener. Classification and regression by randomforest. $R$ News, 2(3):18-22, 2002.

[58] L. P. Lim, N. C. Lau, E. G. Weinstein, A. Abdelhakim, S. Yekta, M. W. Rhoades, C. B. Burge, and D. P. Bartel. The microRNAs of Caenorhabditis elegans. Genes \& Development, 17(8):991-1008, Apr. 2003. 
[59] M. Lindow and A. Krogh. Computational evidence for hundreds of non-conserved plant microRNAs. BMC Genomics, 6, Sep. 2005.

[60] X. Liu, S. He, G. Skogerbø, F. Gong, and R. Chen. Integrated sequence-structure motifs suffice to identify microRNA precursors. Plos One, 7(3):e32797, Jan. 2012.

[61] H. Lodish, A. Berk, C. A. Kaiser, M. Krieger, M. P. Scott, A. Bretscher, H. Ploegh, and P. Matsudaira. Molecular Cell Biology (Lodish, Molecular Cell Biology). W. H. Freeman, 6th edition, Jun. 2007.

[62] R. Lorenz, S. H. Bernhart, C. Höner Zu Siederdissen, H. Tafer, C. Flamm, P. F. Stadler, and I. L. Hofacker. ViennaRNA Package 2.0. Algorithms for Molecular Biology: AMB, 6(1):26, Jan. 2011.

[63] J. Lu, Y. Shen, Q. Wu, S. Kumar, B. He, S. Shi, R. W. Carthew, S. M. Wang, and C.-I. Wu. The birth and death of microRNA genes in Drosophila. Nature Genetics, 40(3):351-5, Mar. 2008.

[64] N. R. Markham and M. Zuker. DINAMelt web server for nucleic acid melting prediction. Nucleic Acids Research, 33(Web Server issue):W577-81, Jul. 2005.

[65] N. R. Markham and M. Zuker. UNAFold: software for nucleic acid folding and hybridization. Methods in Molecular Biology, 453:3-31, Jan. 2008.

[66] A. Mathelier and A. Carbone. Mirena. Bioinformatics, 26(18):2226-2234, Sep. 2010.

[67] D. H. Mathews. Using an RNA secondary structure partition function to determine confidence in base pairs predicted by free energy minimization. $R N A, 10(8): 1178-90$, Aug. 2004.

[68] M. Matrajt. Non-coding RNA in apicomplexan parasites. Molecular and Biochemical Parasitology, 174(1):1-7, Nov. 2010.

[69] J. S. Mattick. Non-coding RNAs: the architects of eukaryotic complexity. EMBO Reports, 2(11):986-91, Nov. 2001.

[70] J. S. Mattick. Challenging the dogma: the hidden layer of non-protein-coding RNAs in complex organisms. BioEssays, 25(10):930-939, Oct. 2003.

[71] J. S. Mattick and I. V. Makunin. Non-coding RNA. Human Molecular Genetics, 15 Spec No:R17-29, Apr. 2006.

[72] N. D. Mendes, S. Heyne, A. T. Freitas, M.-F. Sagot, and R. Backofen. Navigating the unexplored seascape of pre-miRNA candidates in single-genome approaches. Bioinformatics, 28(23):3034-41, Dec. 2012. 
[73] M. Mohri, A. Rostamizadeh, and A. Talwalkar. Foundations of machine learning. MIT Press, Cambridge, MA, 2012.

[74] A. Morgulis, E. M. Gertz, A. A. Schäffer, and R. Agarwala. A fast and symmetric DUST implementation to mask low-complexity DNA sequences. Journal of Computational Biology, 13(5):1028-40, Jul. 2006.

[75] E. G. Moss, R. C. Lee, and V. Ambros. The Cold Shock Domain Protein LIN-28 Controls Developmental Timing in C. elegans and Is Regulated by the lin-4 RNA. Cell, 88(5):637646, Mar. 1997.

[76] J.-W. Nam, J. Kim, S.-K. Kim, and B.-T. Zhang. ProMiR II: a web server for the probabilistic prediction of clustered, nonclustered, conserved and nonconserved microRNAs. Nucleic Acids Research, 34(Web-Server-Issue):455-458, 2006.

[77] J. W. Nam, K. R. Shin, J. Han, Y. Lee, N. V. Kim, and B. T. Zhang. Human microRNA prediction through a probabilistic co-learning model of sequence and structure. Nucleic Acids Research, 33(11):3570-3581, 2005.

[78] K. L. S. Ng and S. K. Mishra. De novo SVM classification of precursor microRNAs from genomic pseudo hairpins using global and intrinsic folding measures. Bioinformatics, 23(11):1321-30, Jun. 2007.

[79] S. Ng Kwang Loong and S. K. Mishra. Unique folding of precursor microRNAs: quantitative evidence and implications for de novo identification. RNA (New York, N.Y.), 13(2):170-87, Feb. 2007.

[80] S. Pfeffer, A. Sewer, M. Lagos-Quintana, R. Sheridan, C. Sander, F. A. Grässer, L. F. van Dyk, C. K. Ho, S. Shuman, M. Chien, J. J. Russo, J. Ju, G. Randall, B. D. Lindenbach, C. M. Rice, V. Simon, D. D. Ho, M. Zavolan, and T. Tuschl. Identification of microRNAs of the herpesvirus family. Nature Methods, 2(4):269-76, Apr. 2005.

[81] J. R. Quinlan. C4.5: programs for machine learning. Morgan Kaufmann Publishers Inc., San Francisco, CA, USA, 1993.

[82] M. Re and G. Valentini. Ensemble Methods: a review. Chapman \& Hall, 2011.

[83] W. Ritchie, D. Gao, and J. E. J. Rasko. Defining and providing robust controls for microRNA prediction. Bioinformatics, 28(8):1058-61, Apr. 2012.

[84] A. J. Scott and M. Knott. A cluster analysis method for grouping means in the analysis of variance. Biometrics, 30(3):507-512, 1974. 
[85] A. Sewer, N. Paul, P. Landgraf, A. Aravin, S. Pfeffer, M. Brownstein, T. Tuschl, E. van Nimwegen, and M. Zavolan. Identification of clustered microRNAs using an ab initio prediction method. BMC Bioinformatics, 6(1):267+, Nov. 2005.

[86] K. D. Taganov, M. P. Boldin, and D. Baltimore. MicroRNAs and immunity: tiny players in a big field. Immunity, 26(2):133-7, Mar. 2007.

[87] S. Tempel and F. Tahi. A fast ab-initio method for predicting miRNA precursors in genomes. Nucleic Acids Research, 40(11):e80, Jun. 2012.

[88] G. Terai, T. Komori, K. Asai, and T. Kin. miRRim: A novel system to find conserved miRNAs with high sensitivity and specificity. RNA, 13(12):2081-2090, Dec. 2007.

[89] M. Toll-Riera, N. Radó-Trilla, F. Martys, and M. M. Albà. Role of low-complexity sequences in the formation of novel protein coding sequences. Molecular Biology and Evolution, 29(3):883-6, Mar. 2012.

[90] T. T. Tran, F. Zhou, S. Marshburn, M. Stead, S. R. Kushner, and Y. Xu. De novo computational prediction of non-coding RNA genes in prokaryotic genomes. Bioinformatics, 25(22):2897-2905, 2009.

[91] I. H. Witten and E. Frank. Data Mining: Practical Machine Learning Tools and Techniques. Morgan Kaufmann, San Francisco, 2nd edition, 2005.

[92] Y. Wu, B. Wei, H. Liu, T. Li, and S. Rayner. MiRPara: a SVM-based software tool for prediction of most probable microRNA coding regions in genome scale sequences. BMC Bioinformatics, 12:107, Jan. 2011.

[93] Y. Xu, X. Zhou, and W. Zhang. MicroRNA prediction with a novel ranking algorithm based on random walks. Bioinformatics, 24(13):i50-8, Jul. 2008.

[94] P. Xuan, M. Guo, X. Liu, Y. Huang, W. Li, and Y. Huang. PlantMiRNAPred: efficient classification of real and pseudo plant pre-miRNAs. Bioinformatics, 27(10):1368-1376, May 2011.

[95] C. Xue, F. Li, T. He, G. P. Liu, Y. Li, and X. Zhang. Classification of real and pseudo microRNA precursors using local structure-sequence features and support vector machine. BMC Bioinformatics, 6, 2005.

[96] X. Yang and L. Li. miRDeep-P: a computational tool for analyzing the microRNA transcriptome in plants. Bioinformatics, 27(18):2614-5, Sep. 2011.

[97] M. Yousef. A comparison study between one-class and two-class machine learning for MicroRNA target detection. Journal of Biomedical Science and Engineering, 03(03):247252, 2010. 
[98] M. Yousef, S. Jung, L. C. Showe, and M. Showe. Learning from positive examples when the negative class is undetermined - microRNA gene identification. Algorithms for Molecular Biology, 3:2, Jan. 2008.

[99] M. Yousef, M. Nebozhyn, H. Shatkay, S. Kanterakis, L. C. C. Showe, and M. K. K. Showe. Combining multi-species genomic data for microRNA identification using a Naive Bayes classifier machine learning for identification of microRNA genes. Bioinformatics, 22:13251334, Mar. 2006.

[100] B. Zhang, X. Pan, G. P. Cobb, and T. A. Anderson. Plant microrna: A small regulatory molecule with big impact. Developmental Biology, 289(1):3 - 16, 2006.

[101] M. Zuker. Mfold web server for nucleic acid folding and hybridization prediction. Nucleic Acids Research, 31(13):3406-3415, Jul. 2003. 
